\title{
AVALIAÇÃO DA APRENDIZAGEM DE ESCOLARES COM DIAGNOSTICO DE TRANSTORNO DE LEITURA
}

\section{EVALUATION OF SCHOOL LEARNING WITH DIAGNOSIS OF READING DISORDER}

\author{
Sayonara Miranda Oliveira ${ }^{1}$ \\ Universidade do Minho - Portugal \\ Tamires Silva Santos 2 \\ Universidade do Estado da Bahia \\ Kleonara Santos Oliveira ${ }^{3}$ \\ Universidade do Estado da Bahia
}

\begin{abstract}
Resumo
A avaliação da aprendizagem escolar vem sendo alvo de muitas pesquisas, por apresentar-se bastante desafiadora no processo ensino e aprendizagem. Esse desafio torna-se ainda maior quando se trata de alunos que apresentam dificuldades mais acentuadas no processo de aquisição das aprendizagens escolares, como é o caso das crianças com diagnóstico de Transtorno de Leitura. Assim, o objetivo principal deste artigo é refletir sobre a avaliação da aprendizagem de escolares com diagnóstico do transtorno. Com vistas a alcançar o objetivo proposto, optou-se por seguir uma abordagem qualitativa, com pesquisa de campo, e como técnica de pesquisa utilizamos a entrevista semiestruturada. A pesquisa foi realizada em uma escola pública do município de Caculé-Bahia, e tivemos como sujeitos duas professoras da rede regular de ensino, que acompanham alunos com o diagnóstico de Transtorno de Leitura, em suas salas de aula. Esse artigo é um recorte do trabalho de conclusão de curso realizado na Universidade do Estado da Bahia - UNEB, Campus XII, no curso de Pedagogia. Constatou-se que
\end{abstract}

\footnotetext{
1 Possui graduação em Psicologia pela Universidade Federal da Paraíba (1994). Atualmente é psicóloga da Prefeitura Municipal de Jequié. É professora auxiliar da Universidade do Estado da Bahia. Tem experiência na área de Psicologia, com ênfase em Educação Organizacional. Especialização em Educação Especial pela Universidade Estadual de Santa Cruz. Mestre em Gestão de Recursos Humanos na Universidade do Minho - Portugal. Aluna do doutorado na universidade do Minho- Portugal.

2 Pedagoga (licenciatura) pela Universidade do Estado da Bahia. Membro do grupo de estudos e pesquisa de educação especial inclusiva, vinculado à Linha de Pesquisa Formação Humana e Gestão do Cuidado na Educação da Universidade do Estado da Bahia (UNEB), Campus XII - Guanambi - Bahia.

${ }_{3}$ Mestranda em Ensino, Linguagem e Sociedade (UNEB), Campus VI. Graduada em Pedagogia pela Universidade do Estado da Bahia (UNEB). Especialista em Neuropsicologia (UFBA); Psicopedagogia Clínica e Institucional (FG/BA); Psicomotricidade Aplicada a Educação (FACIG/MG); Docência do Ensino Superior (FACIG/MG); Práticas Pedagógicas Interdisciplinares (UNEB); Coordenação Pedagógica (UFBA); Gestão Educacional (FHR/BA). Professora Subst. da Universidade do Estado da Bahia - (UNEB), Campus XII, Guanambi. Pesquisadora do Núcleo de Pesquisa e Extensão Educacional Paulo Freire - NEPE/UNEB. Coordenadora da Linha de Pesquisa Formação Humana e a Gestão do Cuidado na Educação (UNEB). Coordenadora Projeto de Extensão: Brinquedoteca (UNEB). Coordenadora do Grupo de estudos e pesquisa em Neurodesenvolvimento e Inclusão (UNEB). Experiência na área de Inclusão Escolar; Avaliação e reabilitação cognitiva e psicomotora. Programas do governo Federal, como: Pacto Nacional pela Alfabetização na Idade Certa (PNAIC) e Plano de Ações Articuladas (PAR).
} 
as práticas avaliativas nas escolas regulares se configuram muito mais com o ato de examinar do que de avaliar, pois não promovem o saber e tampouco apresentam-se como diagnósticas, mas serve para categorizar o aluno, classificá-lo e, por diversas vezes, excluí-lo.

Palavras-chave: Avaliação da Aprendizagem; Transtorno de Leitura; Inclusão.

\begin{abstract}
The evaluation of school learning has been the subject of many researches and studies, since it is quite challenging in the teaching and learning process. This challenge becomes even greater when it comes to students who present greater difficulties in the process of acquiring school learning, as is the case of children with Reading Disorder. Thus, the main objective of this article is to reflect on the evaluation of the learning of students with diagnosis of Reading Disorder. In order to reach the proposed objective, we chose to follow a qualitative approach, with field research, and as a research technique we used the semi-structured interview. The research was carried out in a public school in the city of Caculé-Bahia, and we had as subjects two teachers of the regular network of education, who accompany students with the diagnosis of Reading Disorder in their classrooms. This manuscript is a clipping of the course completion work carried out at the State University of Bahia - UNEB, Campus XII, in the course of Pedagogy. It is noticed that the evaluative practices in the regular schools are configured much more by the act of examining than of evaluating, since they do not promote the knowledge nor they present themselves as diagnostic, but it serves to categorize the student, classifies it and by diverse sometimes delete it.
\end{abstract}

Keywords: Evaluation of Learning; Reading Disorder; Inclusion.

\title{
INTRODUÇÃO
}

Avaliação da aprendizagem escolar na perspectiva inclusiva refere-se a um conjunto de práticas que ocorrem processualmente e de modo diversificado, levando em consideração o desenvolvimento do sujeito avaliado. Nesse sentido, a avaliação da aprendizagem não serve para classificar, rotular e excluir o aluno, quando este não consegue alcançar os objetivos almejados. Segundo Hoffmann (2012), avaliar não é julgar o educando, mas é acompanhar o percurso de vida da criança, durante o qual ocorrem mudanças em múltiplas dimensões com a intenção de favorecer o máximo possível seu desenvolvimento.

Se avaliar crianças com o desenvolvimento típico é desafiador para os professores, avaliar crianças com diagnóstico de Transtorno de Leitura é um desafio ainda maior, pois exige do professor habilidades para identificar no aluno os processos de informação que ocorrem a níveis visuais, auditivos, atencional, conceptual, da fala e sequencial, em diferentes etapas do desenvolvimento (NOGUEIRA e PARRA, 2016). O Transtorno de Leitura é uma designação do DSM-5 (2014), mais popularmente conhecido como dislexia, é um transtorno específico de leitura e por ser transtorno não se configura como atraso 
cognitivo, nem déficit sensorial ou até mesmo por desfavorecimento no âmbito familiar e social.

O principal objetivo desta pesquisa é o de refletir sobre a avaliação da aprendizagem de escolares com diagnóstico de Transtorno de Leitura (TL) na rede regular de ensino. Para desenvolver esse trabalho foi utilizada a abordagem qualitativa, tendo como técnica de coleta de dados a entrevista semiestruturada, realizada com duas professoras da educação básica que possuem alunos com diagnóstico de Transtorno de Leitura, em uma escola municipal da cidade de Caculé no interior do Estado da Bahia. As duas professoras escolhidas como sujeitos da pesquisa, eram as únicas, em toda a cidade, que tinham alunos com o diagnóstico de Dislexia. De acordo com a Secretaria Municipal de Educação, há muitas crianças com suspeita do transtorno, mas com laudo médico, somente nas salas dessas professoras.

Esse artigo foi organizado do seguinte modo: no primeiro momento, abordamos o que é o Transtorno de Leitura, que de acordo com o DSM-V, caracteriza-se por apresentar prejuízo na leitura com dificuldades persistentes para aprender habilidades acadêmicas fundamentais de leitura exata e fluente de palavras e compreensão da leitura. Essa discussão dar-se-á numa perspectiva neuropsicológica.

Em seguida foram levantadas as recomendações propostas por alguns pesquisadores que pesquisam o TL, sobre como deve ser o processo avaliativo destes escolares. Na consecução, foram identificadas as práticas avaliativas utilizadas pelos professores com alunos que possuem transtorno de leitura no município de Caculé Bahia. Por fim, temos as considerações finais desse trabalho.

\section{TRANSTORNO DE LEITURA: CARACTERISTICAS, DIAGNÓSTICO E INCLUSÃO}

O Transtorno de Leitura (TL), popularmente conhecido como dislexia, é um transtorno manifestado por dificuldade na aprendizagem da leitura, independentemente de instrução convencional, inteligência adequada e oportunidade sociocultural. (ROTTA, OHLWEILER, RIESGO, 2016). Ainda para estes, é preciso definir leitura, antes de definirmos dislexia, assim, leitura é entendida como interpretação de qualquer sinal que, chegando aos órgãos dos sentidos, conduza o pensamento a outra situação além dele próprio. A leitura é também a interpretação de sinais gráficos, que determinada comunidade convencionou utilizar para substituir os sinais linguísticos da fala. (ROTTA, OHLWEILER, RIESGO, 2016). 
Os critérios diagnósticos tradicionalmente empregados para transtornos de leitura requerem uma avaliação multidisciplinar específica, envolvendo médicos, psicólogo, fonoaudiólogo e professor. Esse diagnóstico não pode ser determinado por déficits intelectuais, sensoriais e emocionais ou escolarização inadequada; além disso, as dificuldades devem estar presentes em mais de um contexto, isto é, perturbar tanto o desempenho acadêmico como a vida diária (APA, 2002; Organização Mundial da Saúde [OMS], 1993).

De acordo com Alves, Mousinho e Capellini (2011, p. 30),

Atualmente o conceito mais aceito de dislexia é um transtorno específico da aquisição e do desenvolvimento da aprendizagem da leitura, caracterizado por um rendimento em leitura inferior ao esperado para a idade e que não se caracteriza como o resultado direto de comprometimento da inteligência geral, lesões neurológicas, problemas visuais ou auditivos, distúrbios emocionais ou escolarização inadequada.

O escolar com dislexia não necessariamente é uma criança com déficit cognitivo, a sua dificuldade está relacionada à leitura e à escrita, mas, provavelmente, se não houver algum outro transtorno associado, aprenderá os conteúdos escolares sem maiores dificuldades. A leitura, assim como demais atividades mentais ou físicas, depende de comandos associados ao cérebro. Segundo Alves, Mousinho e Capellini (2011, p. 22),

A leitura proficiente depende da ativação integrada e simultânea de diversas redes cerebrais. Segundo os estudos funcionais, o reconhecimento das palavras tem bases neurobiológicas bem estabelecidas, representadas pela ativação da região temporal basal e bilateral. A integração das informações e o processamento fonológico levam à ativação do giro angular e dos giros temporais (médio e superior) esquerdos. A produção da leitura e a compreensão da ativação das regiões frontais.

Esse Transtorno não se configura com Deficiência Intelectual e de nenhum modo afeta a inteligência do sujeito, pois este pode aprender com facilidade os conteúdos ensinados, porém, encontram a limitação na leitura e consequentemente na escrita.

A dislexia pode ser percebida em casa pelos familiares da criança, porém é mais comum que essa descoberta aconteça na escola, nos primeiros anos escolares, no momento em que se inicia o processo de alfabetização. Pois é a partir desse momento que a leitura e escrita começam a fazer parte do universo do aluno de modo mais efetivo. A partir da sua inserção no ciclo de alfabetização é que as dificuldades de leitura vão aparecendo, quando percebem que a criança, que poderia estar progredindo, não se desenvolve de acordo com o esperado para a sua idade, não consegue se identificar com 
os mecanismos da leitura e da escrita, apresentando dificuldades não comuns para sua faixa etária.

A leitura e a escrita são parte da cultura, nós não nascemos para ler e escrever, desenvolvemos essa habilidade por meio de técnicas e para isso precisamos de métodos. "A aprendizagem da escrita não é um processo natural, esta é uma invenção cultural, a construção de uma visualização dos sons da fala não é um instinto. A escrita precisa ser ensinada por meio de métodos que orientem o processo de ler e escrever" (SOARES, 2017).

\section{DIAGNÓSTICO E INTERVENÇÃO}

O diagnóstico é essencial para que haja uma intervenção precisa e adequada, pode ser feito até mesmo antes de a criança começar a ler, mas para isso é preciso cautela e a avaliação deve ser feita por profissionais especializados.

O aluno com TL apresenta características bem particulares em cada etapa escolar. $\mathrm{Na}$ educação infantil, é possível observar fatores preditivos de prováveis futuros quadros disléxicos: dificuldade na aquisição da linguagem oral; dificuldade de memória fonológica; dificuldade em nomear pessoas, cores, objetos e figuras geométricas; representação gráfica aceleradas e pobres; e desinteresse por letras. O início da educação formal é fundamental na identificação do transtorno. Já no primeiro ano observa-se um distanciamento radical entre o que os colegas aproveitam do processo lectográfico e os possíveis alunos disléxicos: os colegas armazenam palavras, fazem associações, descobrem semelhanças e diferenças entre as palavras e têm prazer com essas atividades. Já o aluno com sinais disgráficos não reconhecem as vogais com facilidade, apresentam interesse restrito na produção gráfica, esquiva-se de mostrar o que aprendeu. (ROTTA, FILHO E BRIDI, 2016).

O professor tem uma importante participação no processo de descoberta desse transtorno. Seu olhar e experiência auxiliam positivamente na identificação do TL. O papel do professor não é o de diagnosticar, mas de encaminhar a criança e orientar seus familiares para os cuidados devidos. A dislexia ou Transtorno de Leitura não é uma doença, mas um modo de existir, de funcionar. Cada ser é diferente e precisa ser respeitado em suas peculiaridades. A importância de se fazer um diagnóstico bem feito está na possibilidade de descobrir como aquela criança aprende, como ela funciona, para que assim, o professor e familiares possam ensiná-la do jeito que ela pode aprender, respeitando seu tempo e espaço. 
O diagnóstico, como já citado, deve ser feito por uma equipe multidisciplinar que tenha a participação de profissionais como médico, psicólogo, fonoaudiólogo e pedagogo. Os transtornos de aprendizagem envolvem fatores fisiológicos e cognitivos, portanto, exige o trabalho de uma equipe multidisciplinar especializada. Cabe salientar que a família tem papel importante na identificação desse transtorno, pois a mesma deve fazer parte da vida escolar do educando.

As principais características de uma criança com TL é o atraso na linguagem oral, erros ortográficos, inversão de letras dentro de palavras e dificuldades em distinguir fonemas e grafemas. Além disso, a dificuldade ao ler palavras com mais de uma sílaba, grafia ruim, desprazer ao ler e histórico familiar são traços que devem ser avaliados na identificação desse transtorno.

Conforme a Associação Brasileira de Dislexia (2018), o diagnóstico é alcançado mediante consultas, uma avaliação multidisciplinar, processamento auditivo e audiometria, treinamento auditivo em cabine e exame neurológico. Após a identificação do TL deve ocorrer uma intervenção. A intervenção adequada e, por isso, eficaz, só é possível com uma boa avaliação que leve em consideração todas as condições ecológicas da criança.

Segundo Teles, o Método Fonomímico é bastante apropriado para a alfabetização de alunos com TL. Esse é um método fónico-silábico e multissensorial de desenvolvimento das competências fonológicas, de ensino e reeducação da leitura e da escrita. Outro método muito eficaz é o multissensorial, os métodos de ensino multissensoriais ajudam as crianças a aprender utilizando mais do que um sentido, enfatizam os aspectos sinestésicos da aprendizagem integrando o ouvir e o ver, com o dizer e o escrever. (TELES, 2012)

Devemos levar em consideração o que nos diz Soares (2017) sobre os métodos de alfabetização, não existe método milagroso, mas o professor precisa ter método para ensinar seus alunos, precisa ter clareza sobre onde quer chegar ao ensinar seus meninos e meninas. Por isso, os instrumentos de avaliação da aprendizagem desses alunos devem ser escolhidos de modo que corroborem com este processo de ensino e aprendizagem. O professor deve ensinar, observar, ensinar novamente e assim sucessivamente. $O$ ato de avaliar deve ser paralelo ao de ensinar. 


\section{AVALIAÇÃO DA APRENDIZAGEM DE ESCOLARES COM TRANSTORNO DE LEITURA}

O modo como o professor avalia seus alunos pode definir a ação de educar, ensinar, auxiliar no desenvolvimento. Esse é um procedimento pelo qual o professor toma decisões de como agir frente a dificuldades enfrentadas pelos alunos, para assim, solucioná-las e melhorar cada vez mais suas práticas pedagógicas e o ensino. Avaliar o aluno é, sobretudo, avaliar a si mesmo, seu trabalho docente.

Não se deve relacionar a avaliação da aprendizagem unicamente aos instrumentos classificatórios, como a prova escrita, por exemplo. Não se pode negar que a prova escrita é um instrumento de avaliação da aprendizagem, mas não é o único, e tampouco pode ser usada para classificar os alunos como aprovados ou reprovados, excluindo aqueles que não apresentaram um bom desempenho nas atividades (DEPRESBITERES, TAVARES, 2017).

O valor da avaliação não está no instrumento em si, mas no uso que se faz dele. Mais do que o instrumento, importa o conhecimento que se põe à prova. $E$ toda avaliação envolve decisões éticas. Depresbiteres e Tavares (2017, p. 28), "defendem a ideia de avaliação como forma de emancipação e metacognição". Quando bem utilizada pode auxiliar o aluno no autoconhecimento, numa reflexão que contribui para uma nova ação. $A$ grande meta da avaliação é a ação, e esta ação cria novas possibilidades de ensino e, por isso, de aprendizagem.

A avaliação vista como processual serve como instrumento de diagnóstico das aprendizagens do aluno, o que este sabe, quais suas habilidades, para a partir daí serem provocados novos conhecimentos. Além de servir para comparar o aluno com ele mesmo, com o que não sabia e aprendeu, ou o que foi ensinado e não conseguiu assimilar. Não serve para comparar um aluno com o outro. É o crescimento diário de cada um que deve ser levado em consideração, dia após dia. Se não for assim, não é avaliação, mas exame.

No exame os alunos são frequentemente julgados, e as notas são descontextualizadas da vida de cada um e de suas habilidades. Não se leva em consideração a subjetividade dos educandos. Estes são vistos como sujeitos homogêneos, que devem aprender as mesmas coisas, ao mesmo tempo. O exame é tradicional e amedronta quem está sendo avaliado, é um instrumento de poder ditatorial nas mãos do professor que o utiliza. 
A avaliação, de acordo com Luckesi (2012), ao contrário do exame, é um ato amoroso, que deve servir para acompanhar o aluno passo a passo. O aluno deve ser avaliado frequentemente e com os mais diversos instrumentos: provas escritas e orais, apresentações, atividades individuais e coletivas etc., com vistas ao seu amadurecimento cognitivo. Ainda para Luckesi (2012), a prova continua sendo o grande instrumento avaliativo, causador de grande sofrimento nos alunos, principalmente naqueles que têm algum transtorno de aprendizagem, como é o caso do Transtorno de Leitura.

A Lei Brasileira de Inclusão (LBI) lei 13.146/2015, no Art. 28, capítulo V, incumbe ao poder público, criar medidas para adoção de medidas individualizadas e coletivas em ambientes que maximizem o desenvolvimento acadêmico e social dos estudantes, favorecendo o acesso, a permanência, a participação e a aprendizagem em instituições de ensino.

Todas as pessoas têm direito a inclusão escolar, de acordo com a LBI, e para esta, incluir é acesso, permanência, participação e aquisição de conhecimento. Sendo assim, há que se valorizar o processo de avaliação e adotar medidas favoráveis ao desenvolvimento do aluno. Uma vez que a lei assegura o direito de todos à escola, é mister que a escola se adapte ao aluno, inclusive no processo avaliativo.

Existem algumas medidas para avaliar um aluno com TL, e ainda, este pode contar com o apoio de um mediador. Muitos temem que o mediador facilite a avaliação para o aluno, sem levar em consideração que o papel do mediador é atuar onde o sujeito não consegue. Se o aluno tem dificuldade para ler, o mediador deverá ler para ele, incentivando-o a ler também. Deve incentivar suas respostas, provocar seu pensamento, a fim de que se desenvolva. Além disso, a prova para o escolar com dislexia pode ser oralizada. $\mathrm{O}$ aluno que consegue organizar o pensamento e responder significativamente às questões proposta, é um sujeito que aprendeu, apenas não consegue, ainda, ler e escrever. De acordo com Hoffmann, a avaliação mediadora é um processo espontâneo, sem ser espontaneísta. Ou seja, é espontâneo, enquanto amplia o olhar sobre a criança em suas manifestações diversas singulares do dia-a-dia. (HOFFMANN, 2006).

Para corroborar com esta reflexão, contamos com Santos (2003), quando diz que, devemos lutar pela igualdade toda vez que a diferença nos inferioriza, e é preciso lutar pela diferença, toda vez que a igualdade nos descaracteriza. Remetendo-nos ao tema em questão, como um aluno com TL responderá testes e atividades que envolva a leitura, se ele não consegue ler? Certamente ele não conseguirá realizá-los com sucesso. 
Comtemplando alguns princípios para avaliação de alunos com dislexia, (ARRUDA e ALMEIDA, 2014, p.18), citam: "equilibrar aspectos quantitativos e qualitativos, priorizando os qualitativos quando necessário". Sabe-se que há uma cultura quantitativa que impera sobre a qualitativa na escola. Os alunos com TL nos convidam a repensar essa prática, não para facilitar, mas para humanizar os processos educacionais escolares.

\section{REFLEXÕES SOBRE A PRÁTICA}

Foi realizada uma entrevista semiestruturada com duas professoras, no município de Caculé, no Estado da Bahia, que se localiza mais ou menos a 700 km da Capital Salvador e conta com o número 22.236 de habitantes. Essas professoras foram escolhidas por, nessa cidade, serem as únicas que têm alunos com Transtorno de Leitura devidamente diagnosticados. Aqui, chamaremos as professoras de P1 e P2, com vistas a preservar sua identidade.

As duas professoras são pedagogas e ambas possuem especialização na área de educação, no entanto, nunca participaram de formação sobre escolares com Transtorno de Leitura. Foi perguntado qual o maior desafio no processo de inclusão dessas crianças, elas responderam: "O maior desafio tem sido alfabetizar, dar uma resposta para a família que espera que eu faça um milagre. Mas não tenho formação para isso e trabalho o dia todo, não tenho tempo para estudar tanto" (P1). "Fazer com que a criança acompanhe a turma. Mas eu tenho uma turma com 28 alunos" (P2).

Diante das falas das professoras, percebe-se que são inúmeros os desafios, dentre esses estão, a falta de formação continuada, que é um dever do poder público, como aponta a LBI; salas lotadas; e ainda, sobrecarga de trabalho. As condições docentes não favorecem a inclusão dos alunos. Conforme Arruda e Almeida (2014), o processo de inclusão deve atender a todos sem distinção, mesmo que para isso seja preciso uma reorganização no contexto escolar. Esta reorganização implicaria, principalmente, a melhoria das condições de trabalho docente, sendo assegurado às professoras formação e tempo para estudar, sem que isso lhes acarretassem perda salarial.

Perguntamos sobre o processo de alfabetização, se há algum método específico e que oriente sobre a avaliação da aprendizagem. "Eu utilizo o método fônico, adotado no município e não temos uma orientação específica sobre como avaliar o aluno" (P1).

Segundo Capovilla e Seabra (2013), o Método Fônico baseia-se em um ensino dinâmico do alfabeto que leva o aluno a aprender a codificar a escrita e a decodificá-la na 
fala, que é a leitura. As letras são pronunciadas sempre fazendo a relação fonema/grafema, pautando-se na consciência do som em cada letra da palavra. O Método Fônico deve ser introduzido de modo gradual, com complexidade crescente. Ocorre à medida que a criança vai adquirindo uma boa habilidade de fazer decodificação grafofonêmica fluente, ou seja, depois de ter recebido as instruções explícitas e sistemáticas de consciência fonológica e de correspondência entre grafemas e fonemas. Ao contrário do que dizem, a partir do senso comum, o método fônico nada tem a ver com o método tradicional de ensino, pois nesse método valoriza-se o aluno como centro no processo de alfabetização, parte da palavra que tem sentido para cada sujeito aprendente e o aluno é convidado a ser construtor do seu conhecimento, percebendo, analisando e compreendendo o sons de cada letra e a construção da sílaba e da palavra. Por isso, é mais indicado para o trabalho de alfabetização de alunos com transtornos de leitura.

O método fônico não é um método tradicional, pois o aluno é o centro do processo, ele é o construtor do saber, mediado pelo professor. $O$ que pode tornar o método tradicional é o modo como o professor ministra, a postura do educador fará toda a diferença nesse contexto. Muitos autores, estudiosos de métodos de alfabetização, como Soares (2017), citam que não existe método que seja o melhor, mas é preciso que o professor tenha método para ensinar seus alunos, que seja um conhecedor daquilo que está fazendo.

A professora entrevistada sinaliza a utilização de um método que tem sido bem aceito por entre os estudiosos do desenvolvimento infantil atípico, na atualidade, o que é positivo, no entanto, não diz não receber orientação sobre como avaliar o aluno. A formação de professores sobre Transtornos de Leitura, no Brasil, não parece eficaz. Os professores recebem esses alunos, reconhecem suas limitações, mas, no caso apresentado aqui, não sabem o que fazer diante do desafio de alfabetizá-los e tampouco de avaliá-los.

Inserir não é o mesmo que incluir. Para inserir basta colocar o aluno na escola, mas a inclusão está para além, é preciso bem mais que isso. Para Mantoan (2015), incluir é fazer parte do processo, é aprender, é fazer parte. Para que a criança seja incluída ela precisa participar das atividades propostas e estas devem ser acessíveis a todos. Se o professor contar com boas práticas avaliativas, conseguirá planejar aulas em que seus alunos consigam, cada um a seu modo, contribuir, sentir-se parte, protagonizar. Os métodos de alfabetização não funcionam sem atrelar-se a bons métodos de avaliação. 
Foi perguntado, ainda, como acontece a avaliação da aprendizagem dos seus alunos com TL? A professora P1 respondeu: "Faço da maneira normal, escrita, do mesmo jeito que faço com os demais. Fico com medo de fazer diferente e ser mal interpretada por isso, pelos pais e pela própria escola" (P1).

Como foi dito, a criança com dislexia, a depender do grau do TL, não consegue ler e escrever com fluência. Avaliá-la de forma escrita pode potencializar negativamente seu autoconceito, e ferir sua autoestima, fazendo-a sentir-se inferior e incapaz. A outra professora disse que não atribui nota ao aluno com TL. "Ele faz a mesma avaliação que os demais, mas não dou nota" (P2).

A avaliação feita pelas docentes configura-se, muito mais, como ato de examinar, do que propriamente avaliar. Avaliar deve ser um processo que desencadeia outros processos. Avalia-se para diagnosticar, para observar, para montar um plano de ação de aprendizagem. Avaliar, na concepção defendida por esse artigo, diz respeito ao ato amoroso e cuidadoso, de acompanhamento. Deve ocorre no dia a dia e apontando novos caminhos a serem percorridos pelo docente e pelo discente. "Avaliar não é julgar, mas acompanhar um percurso de vida da criança” (HOFFMANN, 2012, p. 13).

O professor Luckesi, em seu livro Avaliação da Aprendizagem Escolar (2011, p. 65), diz: "Parece que a avaliação tem sido compreendida conceitualmente, mas, de fato, não tem gerado condutas novas entre os educadores". O exame não serve nem para as crianças com desenvolvimento típico, muito menos para as que tem desenvolvimento atípico. Mesmo as crianças com fluidez na aprendizagem da leitura e escrita precisam ser desafiadas, potencializadas, para tanto, também precisam de uma avaliação que venha ao encontro de potencializar o seu desenvolvimento. Examinar, classifica, avaliar, inclui.

A educação faz parte do contexto humano, configura-se como ato de intervenção no mundo, exercício de cidadania. Para Freire (2009), a educação não é a transferência de conhecimentos, mas a criação de possibilidades para a sua própria produção ou construção. É importante que a educação se supere a cada dia, possibilitando cada vez mais o desenvolvimento de habilidades e autonomia do educando.

As experiências avaliativas, tradicionalmente, remetem a uma concepção que classifica as aprendizagens em certo ou errado, retirando do mesmo convívio, pela reprovação, os alunos que aprenderam os conteúdos programados daqueles que, até então, não aprenderam. Sob esse prisma, alguns docentes criam e utilizam a avaliação para excluir, segregar, humilhar. São práticas baseadas no autoritarismo, na punição e na 
imposição de poder, perpetuando assim, de geração em geração a imagem da avaliação como atividade de controle e exclusão.

Para Silva (2017), provas ou testes são fatores negativos de motivação para os estudantes, que, diante da ameaça do professor, se dedicam aos estudos não porque os encaram como sendo importantes, necessários ou prazerosos, mas porque são "ameaçados" pela reprovação. São levados a estudar pelo medo, e por isso utilizam a memória operacional, mas logo descarta a informação, sem atribuir significado prático ao conhecimento.

A avaliação inclusiva, que é aquela que respeita as diferenças de cada sujeito, respalda-se na valorização deste e no seu desenvolvimento emocional, pessoal e cognitivo, buscando formar cidadãos que assumam o protagonismo social, despertando o melhor em cada ser.

\section{ALGUMAS CONSIDERAÇOES}

Com esse artigo pretendeu-se refletir sobre o processo de avaliação da aprendizagem de alunos com Transtorno de Leitura. Com a realização desse trabalho foi possível perceber que os professores acolhem os alunos com Transtorno de Leitura, porém, a sua formação não contempla o conhecimento necessário para realizar a inclusão do seu aluno devidamente. Os processos avaliativos precisam ser ressignificados e não é possível incluir sem avaliar devidamente. Avaliar devidamente, como já fora exposto, tem a ver com um ato amoroso e processual, que direciona o saber e a construção deste.

Vale lembrar que o modo de avaliar a criança com o desenvolvimento neurotípico não serve para todas as crianças, mas a avaliação feita com a criança que têm TL pode ser utilizada com os demais alunos, uma vez que deve levar-se em consideração o lúdico, o concreto, a realidade e objetividade de cada aluno. Nota-se assim que, a avaliação inclusiva é também humanizada e humanizadora.

Além do desafio de formação continuada, as condições de trabalho docente são precárias, no município da pesquisa, uma vez que estes trabalham com salas cheias e não thes sobra tempo para estudar mais.

A avaliação da aprendizagem de alunos com Transtorno de Leitura é uma difícil tarefa, uma vez que, a partir do que foi evidente nessa pesquisa, os ideais teóricos estão sendo, em alguns casos, dissociados das práticas pedagógicas. 
Avaliar suas turmas e a aprendizagem de cada um é avaliar-se a si mesmo, constantemente. Precisamos, nós educadores e educadoras, compreender que, quando o aluno fracassa, nós e todo o sistema educacional fracassa junto. E quando esses avançam e desenvolvem-se, também desenvolvemos juntos.

\section{REFERÊNCIAS}

ABD, Associação Brasileira de Dislexia. (ABD). http://www.dislexia.org.br/areadoaluno/. Acessado em: 01/10/2018.

AMERICAN PSYCHIATRIC ASSOCIATION. (APA). Manual diagnóstico e estatístico de transtornos mentais 5a Edição (DSM-V). Porto Alegre: Artmed; 2013.

ARRUDA, Marco Antônio; ALMEIDA, Mauro de (Orgs). Cartilha de Inclusão Escolar Baseada em Evidências Científicas. Ribeirão Preto e São Pedro - SP, 2-14. Disponível em: < http:// dislexia.org.br/pdf/cartilha.pdf>. Acesso em: 10/ 10/2018.

BRASIL. Constituição da República Federativa do Brasil. Brasília: Imprensa Oficial, 1988. Disponível em: http://www2.camara.leg.br/legin/fed/consti/1988/constituicao-1988-5outubro-1988-322142-publicacaooriginal-1-pl.html. Acesso em: 20/09/2018.

BRASIL. Ministério da Educação. Diretrizes nacionais para a educação especial na educação básica/ Secretaria de Educação Especial - MEC; SEESP, 2001. Disponível em: http://portal.mec.gov.br/seesp/arquivos/pdf/diretrizes.pdf. Acesso em: 20/09/2018.

BRASIL. Lei n`9.394/96. Lei das Diretrizes e Bases da Educação Nacional (LDB). Brasília-DF, $1996 . \quad$ Disponível em: http://portal.mec.gov.br/seep/arquivos/pdf/lei9.394_Idbn.pdf. Acessado em: 20/09/2018.

BRASIL. Lei $n^{\circ} 13.146 / 15$. Lei Brasileira de Inclusão (LBI). Brasília-DF, 2015. Acesso em: http://www.planalto.gov.br/CCIVIL_03/_Ato2015-2018/2015/Lei/L13146.htm

CAPOVILLA, Fernando César; SEABRA, Alessandra Gotuzo. Problemas de Leitura e escrita: como identificar, prevenir e remediar numa abordagem fônica. 4. ed. São Paulo: Memnon, 2012.

DEPRESBITERES, L. TAVARES, M. R. Diversificar é preciso: Instrumentos e Técnicas de avaliação da aprendizagem. Senac. 2017.

FREIRE, Paulo. Pedagogia da Autonomia: saberes necessários a prática educativa. São Paulo: Paz e Terra, 2009.

HOFFMANN, Jussara. Avaliação e Educação Infantil.. Porto Alegre: Mediação, 2012.

LUCKESI, Cipriano Carlos. Avaliação da aprendizagem: estudos e proposições. 22.ed. - São Paulo: Cortez, 2011.

NOGUEIRA, L. M. Lourenço. PARRA, C. Regina. Dislexia: Um desafio para o professor. Psicologia pt. ISSN. 1646-6977, 2016. http://www.psicologia.pt/artigos/textos/A1030.pdf . Acesso em 21/09/2018. 
ROTTA, N, Tellechea; OHLWEILER, L. RIESGO, R dos Santos. Transtornos de aprendizagem: abordagem neurobiológica e multidisciplinar. -2 ed. - Porto Alegre: Artmed, 2016.

SILVA, R, Faria da. Avaliação da aprendizagem escola de acordo com a concepção psicopedagógica. Revista Cederj. 2017. Cederj. Issn 1984. 62.90

SOARES, Magda. Alfabetização a questão dos métodos. 1 ed. - São Paulo, Contextos, 2017.

TELES, Paula. Método Fonomímico Paula Teles. In: Colóquio de Psicologia e Educação. 2012, [s.1.]. Actas. Disponível em: <httpp//www.clinicadislexia.com/textos.asp >. Acesso em: 21/09/2018.

Artigo recebido em: 17 de janeiro de 2019 Aceito para publicação em: 31 de março de 2019 